$$
\text { CONF- } 95 / 182--14
$$

\title{
ROTATIONAL AND MAGNETIC SHEAR STABILIZATION OF MAGNETOHYDRODYNAMIC MODES AND TURBULENCE IN DIII-D HIGH PERFORMANCE DISCHARGES
}

by

L.L. LAO, K.H. BURRELL, T.S. CASPER, V.S. CHAN, M.S. CHU, J.C. DeBOO, E.J. DOYLE, R.D. DURST, C.B. FOREST, C.M. GREENFIELD, R.J. GROEBNER, F.L. HINTON, Y. KAWANO, E.A. LAZARUS, Y.R. LIN-LIU, M.E. MAUEL, W.H. MEYER, R.L. MILLER, G.A. NAVRITIL, T.H. OSBORNE, Q. PENG, C.L. RETTIG, G. REWOLDT, T.L. RHODES, B.W. RICE, D.P. SCHISSEL, B.W. STALLARD, E.J. STRAIT, W.M. TANG, T.S. TAYLOR, A.D. TURNBULL, R.E. WALTZ, and The DIII-D TEAM

\author{
DISCLAIMER
}

This report was prepared as an account of work sponsored by an agency of the United States Government. Neither the United States Government nor any agency thereof, nor any of their employees, makes any warranty, express or implied, or assumes any legal liability or responsibility for the accuracy, completeness, or usefulness of any information, apparatus, product, or process disclosed, or represents that its use would not infringe privately owned rights. Reference herein to any specific commercial product, process, or service by trade name, trademark, manufacturer, or otherwise does not necessarily constitute or imply its endorsement, recommendation, or favoring by the United States Government or any agency thereof. The views and opinions of authors expressed herein do not necessarily state or reflect those of the United States Government or any agency thereof. 


\section{DISCLAIMER}

This report was prepared as an account of work sponsored by an agency of the United States Government. Neither the United States Government nor any agency thereof, nor any of their employees, makes any warranty, express or implied, or assumes any legal liability or responsibility for the accuracy, completeness, or usefulness of any information, apparatus, product, or process disclosed, or represents that its use would not infringe privately owned rights. Reference herein to any specific commercial product, process, or service by trade name, trademark, manufacturer, or otherwise, does not necessarily constitute or imply its endorsement, recommendation, or favoring by the United States Government or any agency thereof. The views and opinions of authors expressed herein do not necessarily state or reflect those of the United States Government or any agency thereof. 


\section{DISCLAIMER}

Portions of this document may be illegible in electronic image products. Images are produced from the best available original document. 
GA-A22258

\section{ROTATIONAL AND MAGNETIC SHEAR STABILIZATION OF MAGNETOHYDRODYNAMIC MODES AND TURBULENCE IN DIII-D HIGH PERFORMANCE DISCHARGES}

by

L.L. LAO, K.H. BURRELL, T.S. CASPER, ${ }^{*}$ V.S. CHAN, M.S. CHU, J.C. DeBOO, E.J. DOYLE, ${ }^{\dagger}$ R.D. DURST, ${ }^{\ddagger}$ C.B. FOREST, C.M. GREENFIELD, R.J. GROEBNER, F.L. HINTON, Y. KAWANO, § E.A. LAZARUS, I Y.R. LIN-LIU, M.E. MAUEL, ${ }^{\circ}$ W.H. MEYER, ${ }^{*}$ R.L. MILLER, G.A. NAVRITIL, $\triangle$ T.H. OSBORNE, Q. PENG, C.L. RETTIG, ' G. REWOLDT, ${ }^{\ominus}$ T.L. RHODES, ${ }^{\dagger}$ B.W. RICE, ${ }^{*}$ D.P. SCHISSEL, B.W. STALLARD, ${ }^{\star}$ E.J. STRAIT, W.M. TANG, ${ }^{\ominus}$ T.S. TAYLOR, A.D. TURNBULL, R.E. WALTZ, and The DIII-D TEAM

This is a preprint of an invited paper to be presented at the ThirtySeventh American Physical Society Annual Meeting, Division of Plasma Physics, November 6-10, 1995, Louisville, Kentucky and to be published in Phys. Plasmas.

*Lawrence Livermore National Laboratory, Livermore, California.

tUniversity of California, Los Angeles, California.

FUniversity of Wisconsin, Madison, Wisconsin.

\$Japan Atomic Energy Research Institute, Ibaraki-ken, Japan.

loak Ridge National Laboratory, Oak Ridge, Tennessee.

${ }^{\Delta}$ Columbia University, New York, New York.

Princeton Plasma Physics Laboratory, Princeton, New Jersey.

Work supported by

the U.S. Department of Energy

under Contract Nos. DE-AC03-89ER51114, W-7405-ENG-48,

DE-AC05-84OR21400, and Grant Nos. DE-FG02-89ER53297 and DE-FG03-86ER53266

GA PROJECT 3466

AUGUST 1996 


\section{ABSTRACT}

The confinement and the stability properties of the DIII-D tokamak [Plasma Phys. and Contrl. Nucl. Fusion Research, 1986 (International Atomic Energy Agency, Vienna, 1987), Vol. 1, p. 159] high performance discharges are evaluated in terms of rotational and magnetic shear with emphasis on the recent experimental results obtained from the negative central magnetic shear (NCS) experiments. In NCS discharges, a core transport barrier is often observed to form inside the NCS region accompanied by a reduction in core fluctuation amplitudes. Increasing negative magnetic shear contributes to the formation of this core transport barrier, but by itself is not sufficient to fully stabilize the toroidal drift mode (trapped-electron- $\eta_{i}$ mode) to explain this formation. Comparison of the Doppler shift shear rate to the growth rate of the $\eta_{i}$ mode suggests that the large core ExB flow shear can stabilize this mode and broaden the region of reduced core transport. Ideal and resistive stability analysis indicates the performance of NCS discharges with strongly peaked pressure profiles is limited by the resistive interchange mode to low $\beta_{\mathrm{N}} \leq 2.3$. This mode is insensitive to the details of the rotational and the magnetic shear profiles. A new class of discharges which has a broad region of weak or slightly negative magnetic shear (WNS) is described. The WNS discharges have broader pressure profiles and higher $\beta$ values than the NCS discharges together with high confinement and high fusion reactivity. 


\section{INTRODUCTION AND MOTIVATION}

Advanced plasma configurations with good confinement, improved stability at high $\beta$, and large fraction of well aligned bootstrap current have the potential to provide a compact and economically attractive fusion reactor. One of the leading scenarios for steady state advanced tokamak operation is the negative central magnetic shear (NCS) configuration. ${ }^{1,2}$ In this paper, we identify two of the key elements favorable for stability and confinement commonly found in the high performance discharges in the Doublet III-D (DIII-D) tokamak, ${ }^{3}$ magnetic shear and ExB flow shear, and discuss their stabilization roles in the performance of these discharges with emphasis on the recent experimental results obtained from the NCS experiments. Here, E and B denote the electric and the magnetic field, the magnetic shear is defined as $s=\rho q^{\prime}(\rho) / q, q$ is the safety factor, and $\rho$ the plasma normalized radius.

In these experiments, low confinement mode (L-mode) and high confinement mode (H-mode) NCS discharges are reproducibly obtained by injecting neutral beams very early in the current ramp of a low density target plasma. ${ }^{4}$ Strong peaking of ion temperature, $\mathrm{T}_{\mathrm{i}}$, and plasma toroidal rotation frequency, $\Omega_{\phi}$, are often observed in the negative magnetic shear region as a consequence of the formation of an internal transport barrier. ${ }^{5}$ In discharges with an L-mode edge, in addition to peaking of $T_{i}$ and $\Omega_{\phi}$, strong peaking of plasma electron density, $n_{e}$, is also observed. ${ }^{6}$ This strong increase in central $n_{e}$, but not $T_{i}$, is also observed in the tokamak fusion test reactor (TFTR) ${ }^{7}$ NCS discharges ${ }^{8}$ and has previously been observed in the DIII-D high $\beta_{\mathrm{P}}$ discharges ${ }^{9}$ which have a weak central magnetic shear with $q(0)>2$. Because of their large central $\mathrm{T}_{\mathrm{i}}$ and pressure, both $\mathrm{L}-$ and $\mathrm{H}$-mode NCS discharges have high fusion reactivity. ${ }^{10}$

In this paper, we examine the roles that magnetic shear and ExB flow shear play in the formation of the core transport barrier in the DIII-D NCS discharges. It has been suggested $2,11,12$ that stabilization of toroidal drift mode (trapped-electron- $\eta_{i}$ mode) by NCS may lead to improved core confinement. Increasing negative central magnetic shear contributes to the formation of the core transport barrier. However, while detailed comparison of the toroidal drift mode stability with our experimental data indicates some stabilizing effects, this stabilization is insufficient to explain the width of the region of reduced core transport. Comparison of the Doppler shift shear rate to the growth rate of this mode shows that the strong increase of core ExB flow shear during the transport barrier formation is sufficient to stabilize this mode and 
likely plays a role in broadening the region of reduced core transport. The measured reduction in the core fluctuation level is consistent with the calculated stabilization of the mode.

The reduced transport inside the NCS region can lead to discharges with very peaked pressure profiles $\mathrm{p}(0) /\langle\mathrm{p}\rangle>5$, which almost always disrupt when $\beta_{\mathrm{N}}$ reaches values of 2.0 to 2.5 . Here, $\beta_{\mathrm{N}} \equiv \beta_{\mathrm{T}} /\left(\mathrm{I}_{\mathrm{p}} / \mathrm{aB}\right)(\%-\mathrm{m}-\mathrm{T} / \mathrm{MA})$ is the normalized beta, $\mathrm{p}(0)$ and $\langle\mathrm{p}\rangle$ denote the central and the average plasma pressure, $\beta_{\mathrm{T}}$ is the plasma toroidal beta, $I_{p}$ is the plasma current, $B$ is the vacuum toroidal magnetic field at the geometric center of the last closed flux surface, and a is the minor radius of the last closed flux surface. The disruptions are preceded by a fast growing rotating magnetic precursor with toroidal mode number $n=1$ and a growth time $\gamma^{-1} \approx 0.1-0.3 \mathrm{~ms}$, which approaches ideal time scales. Ideal and resistive stability of these NCS plasmas are studied using the GATO ${ }^{13}$ and the MARS ${ }^{14}$ codes with both experimentally reconstructed as well as simulated equilibria. The termination event cannot be explained by a simple picture of instability to an ideal $n=1$ mode. The value of critical $\beta_{\mathrm{N}}$ unstable to the ideal $n=1$ mode is $10-20 \%$ above the experimental values. The termination is likely the outcome of a resistive interchange instability coupling to more global modes such as the double tearing mode or the ideal modes.

In these DIII-D NCS experiments, a new class of discharges which have a broad region of weak or slightly negative magnetic shear (WNS) has also been developed. It is characterized by a broader pressure profile with $\mathrm{p}(0) /\langle\mathrm{p}\rangle \sim 3$. These discharges have good confinement, high fusion reactivity, large fraction of bootstrap current, but higher $\beta$ values than NCS discharges. Values of $\beta_{\mathrm{N}}>4.5$ and $H>3.5$ have been obtained in these discharges which are among the highest values achieved by an $\mathrm{H}$ - or a very high confinement mode (VH-mode) discharge in DIII-D. Here, $H=\tau_{\mathrm{E}} / \tau_{\text {ITER-89P }}$ is the confinement enhancement factor, $\tau_{\mathrm{E}}$ is the plasma experimental global energy confinement time, and $\tau_{\text {ITER-89P }}$ is the predicted L-mode energy confinement time based on the ITER-89P confinement scaling calculation. 15

The role of magnetic and ExB flow shears in the formation of the core transport barrier is examined in Section II together with a discussion of the density fluctuation measurements. In Section III, the magnetohydrodynamic (MHD) stability of NCS discharges is examined. In Section IV, WNS discharges are discussed. A summary of the results is given in Section V. 


\section{CORE TRANSPORT BARRIER FORMATION IN NCS DISCHARGES}

One of the defining characteristics of high performance DIII-D NCS discharges is the strong peaking of $T_{i}$ and $\Omega_{\phi}$ in the negative shear region. This is illustrated in Fig. 1(a-c). Starting from a low target density $\mathrm{n}_{\mathrm{e}} \sim 1 \times 10^{19} \mathrm{~m}^{-3}$ discharge, $4.6 \mathrm{MW}$ of neutral beam power is injected into the plasma early in the current ramp phase starting at $300 \mathrm{~ms}$. This delays the inductive current penetration into the plasma core and results in a NCS plasma with $q_{0}-q_{\min }>0$ as shown in Fig. 1(b). Here, $q_{0}$ and $q_{\min }$ are the axial and the minimum safety factor. The $q$ profile is reconstructed from equilibrium analysis using internal magnetic field line pitch angle measurements from a 16-channel Motional Stark Effect (MSE) system ${ }^{16}$ and the EFIT code. 17 As illustrated in Fig. 1(c), shortly after the current flat-tops at $1 \mathrm{~s}, \mathrm{~T}_{\mathrm{i}}$ inside the NCS region at $\rho$ $\sim 0.15$ and 0.3 increases sharply preceded by a rise in $q_{0}-q_{\min }$. An almost simultaneous rise of $\Omega_{\phi}$ is also observed in the same region. The sharpest rise occurs in the region where the negative magnetic shear is strong. The beam power $P_{N B}$ is held constant at $4.6 \mathrm{MW}$. During this phase, the central electron temperature $T_{e}(0)$ increases from 2.5 to $4.0 \mathrm{keV}$. The change in $n_{e}$ is small. As shown in Fig. 1(b), this formation of the core transport barrier also leads to an increase in the global energy confinement time as measured by the ratio of $\tau_{\mathrm{E}} / \tau_{\text {ITER-89P. This core transport }}$ barrier formation is independent of the edge transport barrier formed after the discharge makes a transition into the $\mathrm{H}$-mode phase around $1.31 \mathrm{~s}$ as shown in Fig. 1(b).

Increasingly negative magnetic shear contributes to the formation of this core transport barrier. This is illustrated by comparing two discharges shown in Fig. 1. This second discharge shown in Figs. 1(d) through 1(f) has parameters similar to the one show in Fig. 1(a-c) but is injected with a slightly smaller amount of beam power $P_{\mathrm{NB}}=4.2 \mathrm{MW}$. This results in a weaker negative magnetic shear in the plasma core as indicated by a smaller value of $q_{0}-q_{m i n}$ shown in Fig. 1(e). As shown in Fig. 1(f), $T_{i}$ only increases weakly in this case prior to the onset of the $\mathrm{H}-$ mode at $1.31 \mathrm{s.}$.

The strong increase in $T_{i}$ and $\Omega_{\phi}$ in the negative magnetic shear region is illustrated in Fig. 2(a-c) where the $T_{i}, \Omega_{\phi}$, and q profiles are shown for the discharge in Fig. 1(a-c). Profiles from three times are shown; before the formation of the core transport barrier during the 

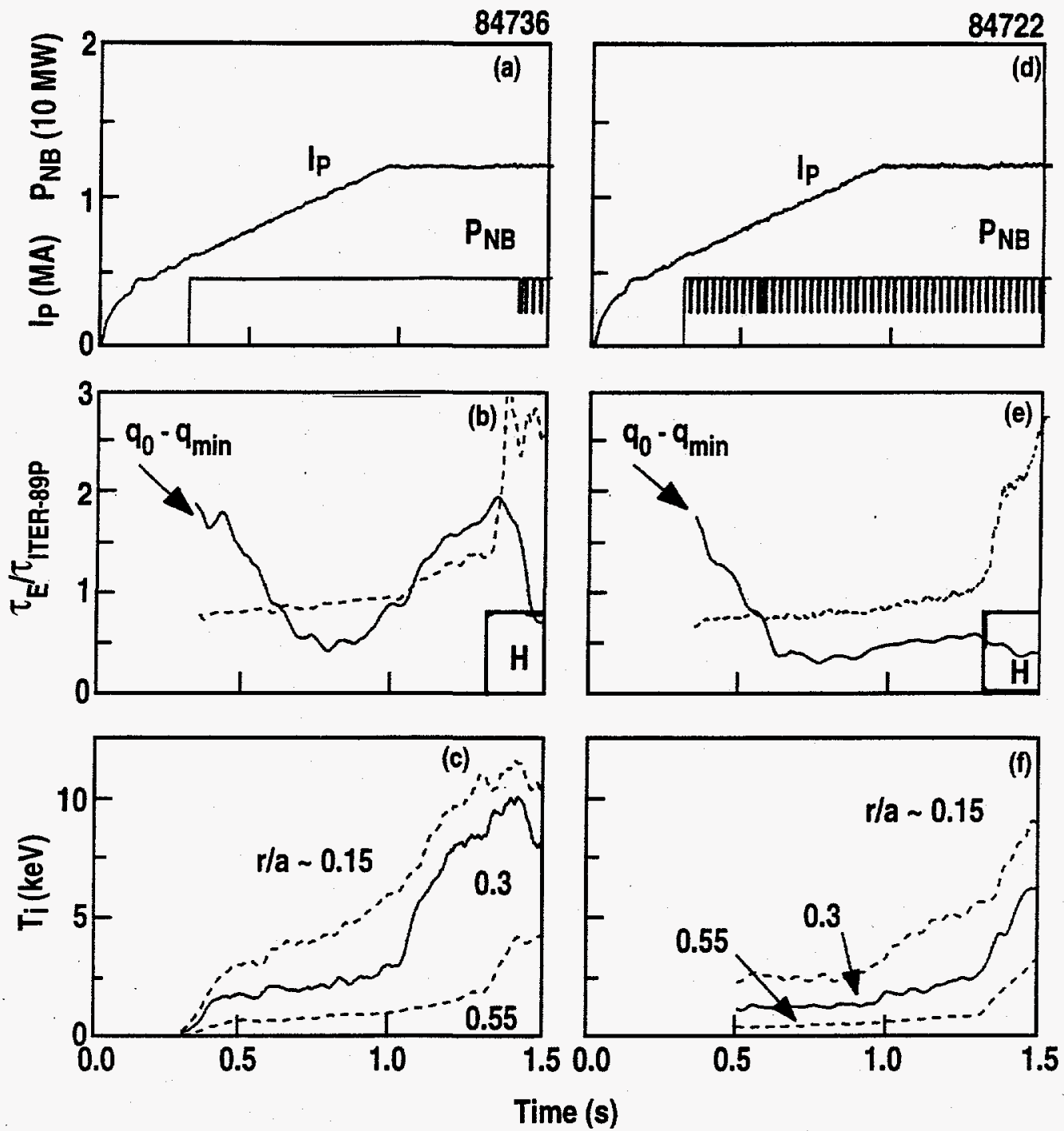

FIG. 1. Comparison of temporal evolution of two NCS discharges with different magnetic shears and slightly different beam powers 84736 and 84722 . (a) Plasma current $I_{P}$ and injected neutral beam power, $P_{\mathrm{NB}}$ for 84736 ; (b) difference between axial safety factor and minimum safety factor $\mathrm{q}_{0}-\mathrm{q}_{\mathrm{min}}$ and energy confinement time normalized with respect to the L-mode ITER-89P scaling

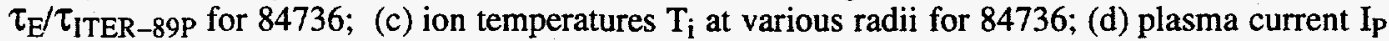
and injected neutral beam power, $P_{N B}$ for 84722 ; (e) difference between axial safety factor and minimum safety factor $q_{0}-q_{\min }$ and energy confinement time normalized with respect to the

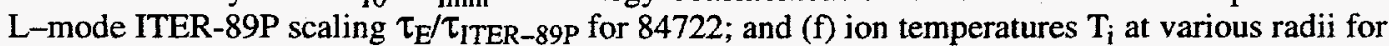
84722.

$\mathrm{L}$-mode, time $\mathrm{t}=1.0 \mathrm{~s}$; after the formation of the transport barrier still during the $\mathrm{L}$-mode, time $\mathrm{t}=1.2 \mathrm{~s}$; and during the $\mathrm{H}$-mode time, $\mathrm{t}=1.4 \mathrm{~s}$. There is an additional large increase of $\mathrm{T}_{\mathrm{i}}$ and $\Omega_{\phi}$ across the entire profile at $t=1.4 \mathrm{~s}$, as expected from the edge transport barrier formation after the $\mathrm{H}$-mode transition around $1.31 \mathrm{~s}$. 

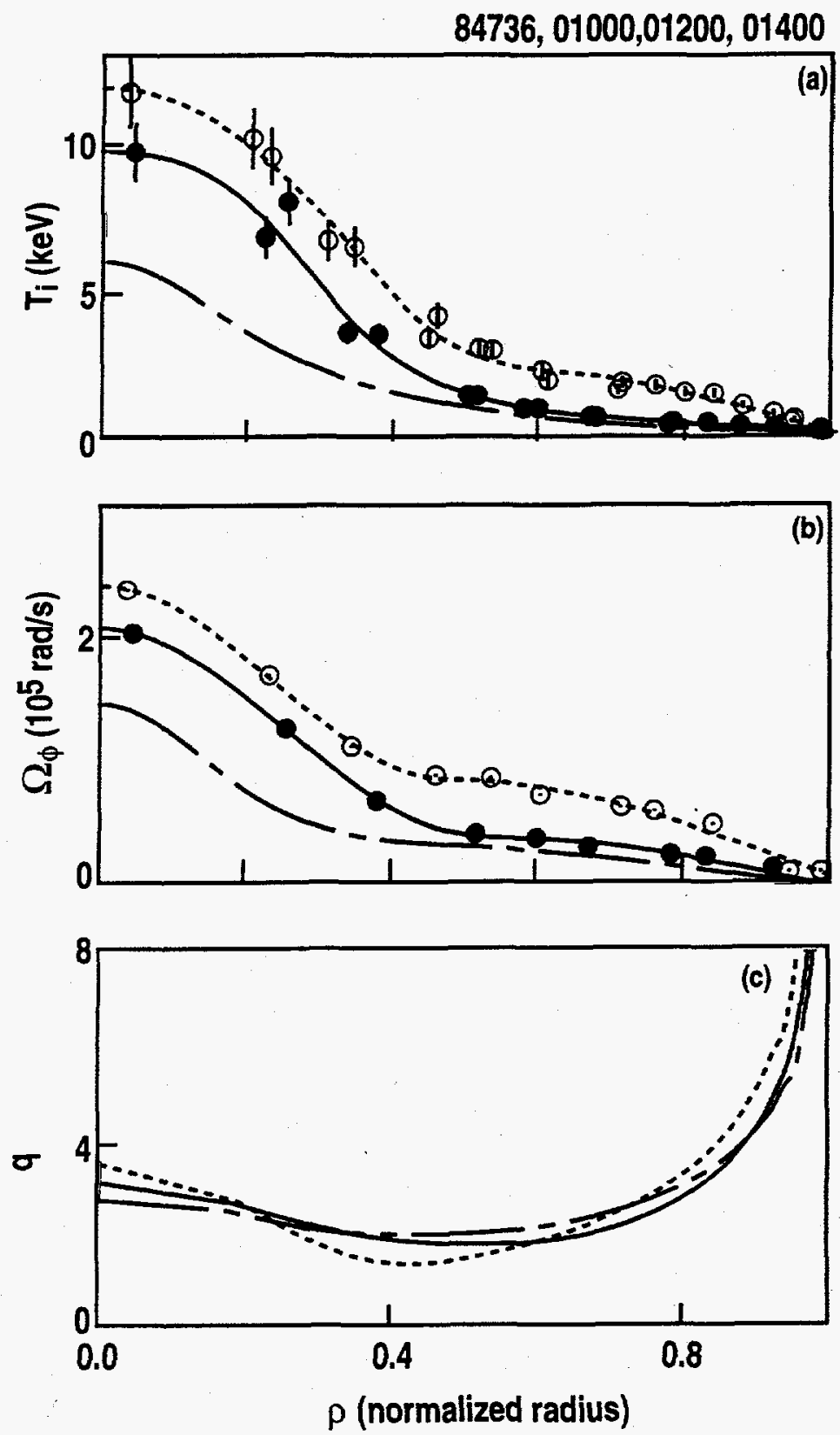

FIG. 2. Comparison of radial profiles of (a) ion temperature, (b) toroidal rotation frequency, and (c) safety factor for discharge 84736 at the L-mode time $1.0 \mathrm{~s}$ before the transport barrier formation (chain-dashed curves), at the L-mode time $1.2 \mathrm{~s}$ after the transport barrier formation (solid curves and solid circles), and at the $\mathrm{H}$-mode time $1.4 \mathrm{~s}$ (dashed curves and open circles).

As expected, the sharp rise of $T_{i}$ in the plasma core implies a significant reduction in the transport. We compare the thermal diffusivites calculated from time-dependent power balance analysis in Fig. 3. In the region $\rho<0.5$, there is a significant reduction of the ion thermal 

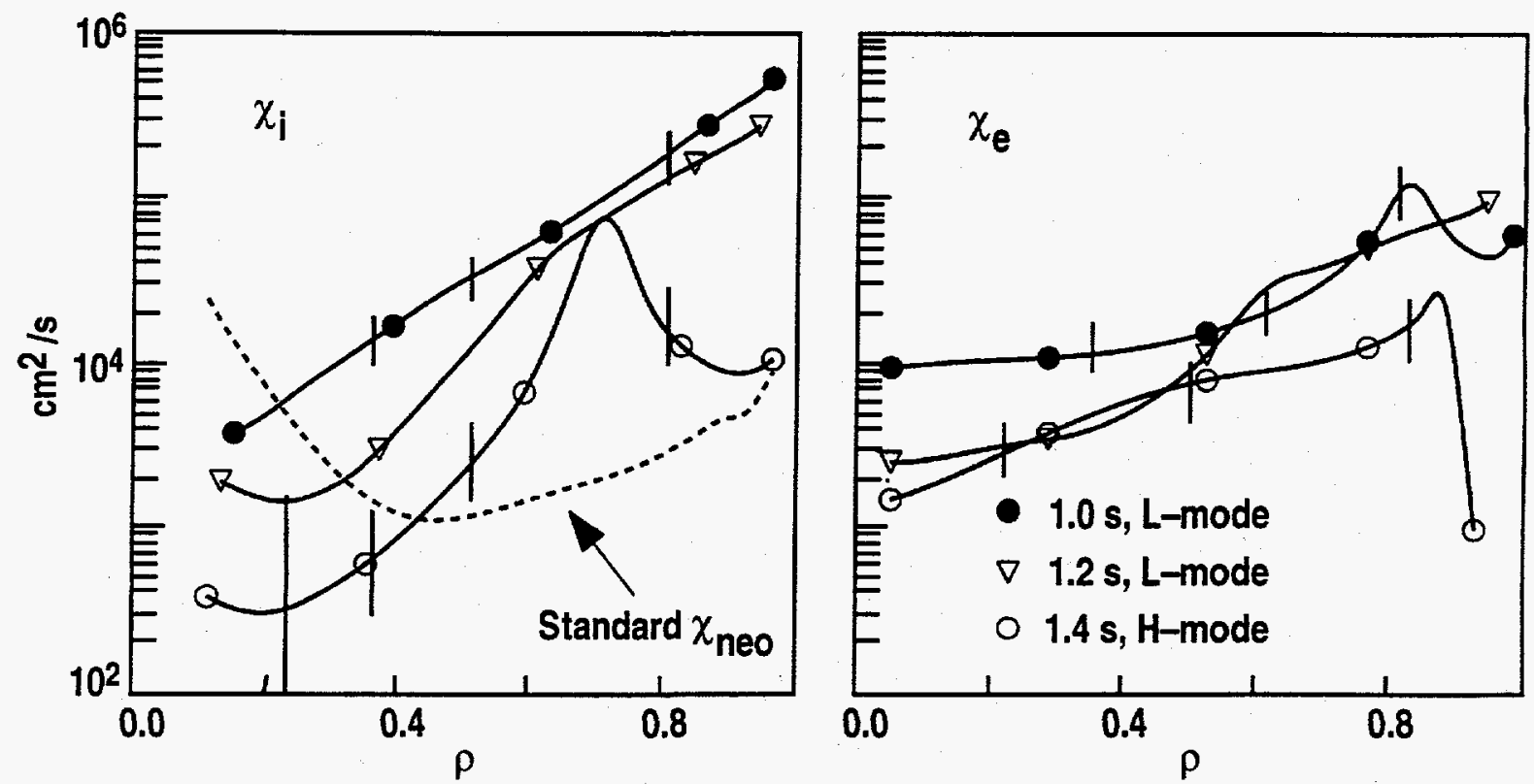

FIG. 3. Comparison of ion and electron thermal diffusivities $\chi_{i}$ and $\chi_{e}$ at the $L$-mode time $1.0 \mathrm{~s}$ (solid circles) before the transport barrier formation, at the L-mode time $1.2 \mathrm{~s}$ (open triangles) after the formation, and at the H-mode time $1.4 \mathrm{~s}$ (open circles) after the formation. The standard neoclassical ion thermal diffusivity $\chi_{\text {neo }}$ is shown in dashed curve.

diffusivity $\chi_{\mathrm{i}}$. This reduction of $\chi_{\mathrm{i}}$ is continuous after the formation of the core transport barrier near time $t=1.03 \mathrm{~s}$. Around $\rho \sim 0.3$ where the negative magnetic shear is strong, $\chi_{i}$ is reduced to near the neoclassical value. In this region, the uncertainty in the determination of $\chi_{i}$ is large since ion thermal conduction loss only represents a small fraction of the beam input power. Inside $\rho \leqslant 0.15$, where the ion poloidal gyroradius becomes comparable to the $T_{i}$ gradient scale length and the ion banana width becomes comparable to the radial distance from the magnetic axis, the standard neo-classical approximation becomes inaccurate and over-estimates the ion thermal diffusivity. The electron thermal diffusivity, $\chi_{\mathrm{e}}$, is also reduced in the negative magnetic shear region, although not as dramatically as $\chi_{i}$. Both $\chi_{i}$ and $\chi_{e}$ in the plasma outer region $\rho>$ 0.8 are reduced in the $\mathrm{H}$-mode phase due to the formation of the edge transport barrier.

Although increasing the level of negative magnetic shear contributes to the formation of the core transport barrier, detailed kinetic stability analyses using the FULL code, 18 with experimentally reconstructed equilibria and measured profiles as inputs, suggest that stabilization effect of the toroidal drift mode (trapped-electron- $\eta_{i}$ mode) by negative central magnetic shear is not sufficient to explain the core transport barrier formation. In Fig. 4, the growth rates of the $\eta_{i}$ mode, $\gamma_{\eta i}$, at the two timeslices before and after the formation of the core transport barrier at 


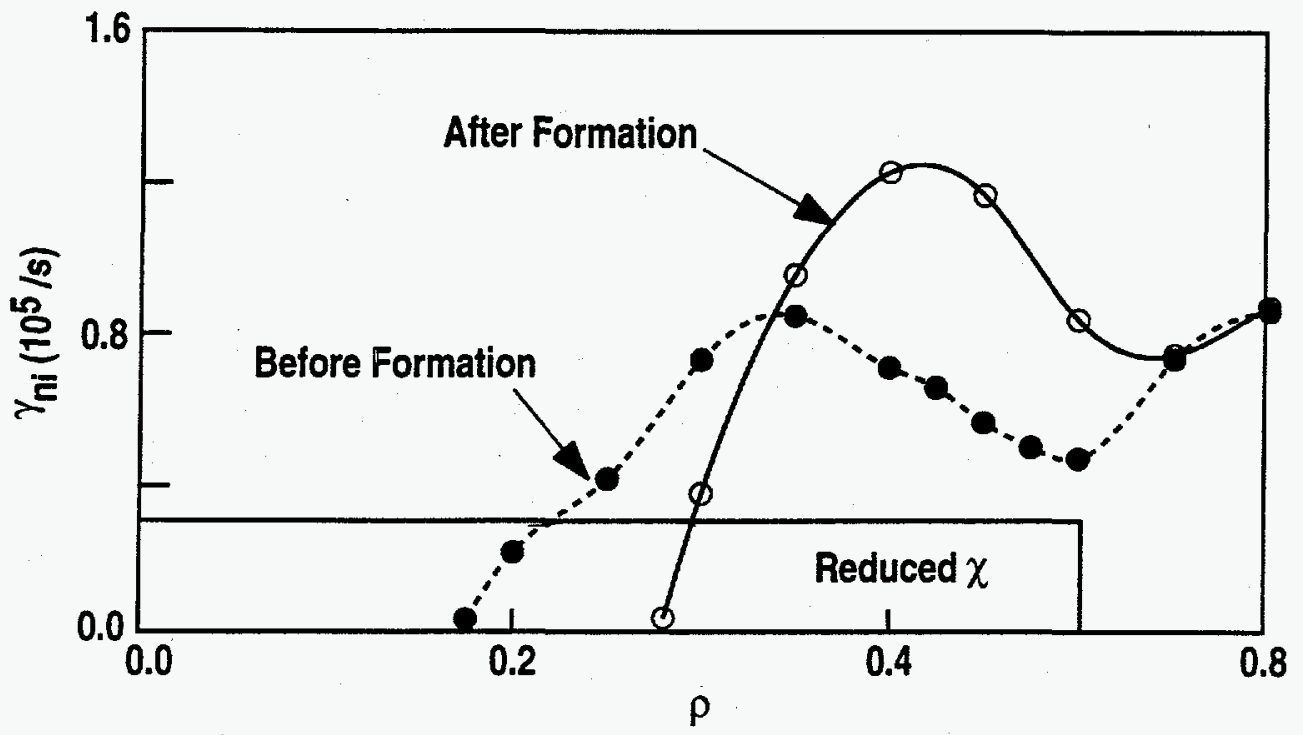

FIG. 4. Comparison of the growth rates of the toroidal drift mode (trapped-electron- $\eta_{i}$ mode), $\gamma_{\eta_{i}}$, before the formation of the core transport barrier at $1.0 \mathrm{~s}$ (solid circles) and after the formation (open circles) at $1.2 \mathrm{~s}$. The region of reduced thermal diffusivity $\chi$ is also shown.

$\mathrm{t}=1.0 \mathrm{~s}$ and $\mathrm{t}=1.2 \mathrm{~s}$ for the discharge shown in Fig. 1(a-c) are compared. These calculations are done with $\Omega_{\phi}=0, \mathrm{k}_{\theta} \rho_{\mathrm{i}}=0.47$, a carbon impurity species and a Maxwellian beam species. Although the stable zone expands from $\rho \sim 0.18$ at $\mathrm{t}=1.0 \mathrm{~s}$ to $\rho \sim 0.28$ at $\mathrm{t}=1.2 \mathrm{~s}$, it is not sufficient to fully explain the width of the region of transport reduction, which extends to $\rho=0.5$ as shown in Fig. 3. Kinetic stability analysis at the timeslice $t=1.2 \mathrm{~s}$ using a simulated monotonic q profile indicates that the negative central magnetic shear does contribute to the stabilization of the toroidal drift mode. Without the negative central shear, the stable zone is found to shrink from $\rho \sim 0.28$ to $\rho \sim 0.2$.

The reduction of transport over the region observed is consistent with stabilization of microturbulence from ExB flow shear. As shown in Fig. 2(b), strong peaking of $\Omega_{\phi}$ is observed inside the negative shear area as the core transport barrier is formed. This together with the rise of poloidal rotation leads to a strong increase of ExB flow shear, $\partial / \partial \rho\left(E_{\mathrm{r}} / \mathrm{RB}_{\theta}\right),{ }^{19}$ in the plasma core. The effects of the ExB flow shear on the stabilization of the toroidal drift mode is estimated by comparing the Doppler shift shear rate, $\gamma_{E}=(\rho / q) \partial / \partial \rho\left(E_{\mathrm{r}} / R B_{\theta}\right),{ }^{20}$ to the growth rate of the mode, $\gamma_{\eta \mathrm{i}}$. The results of that comparison are summarized in Fig. 5. Here, $\mathrm{E}_{\mathrm{r}}$ is the radial component of $E, R$ is the major radius, and $B_{\theta}$ is the poloidal magnetic field. Before the formation of the core transport barrier at $t=1.0 \mathrm{~s}$, the two rates are comparable. After the 

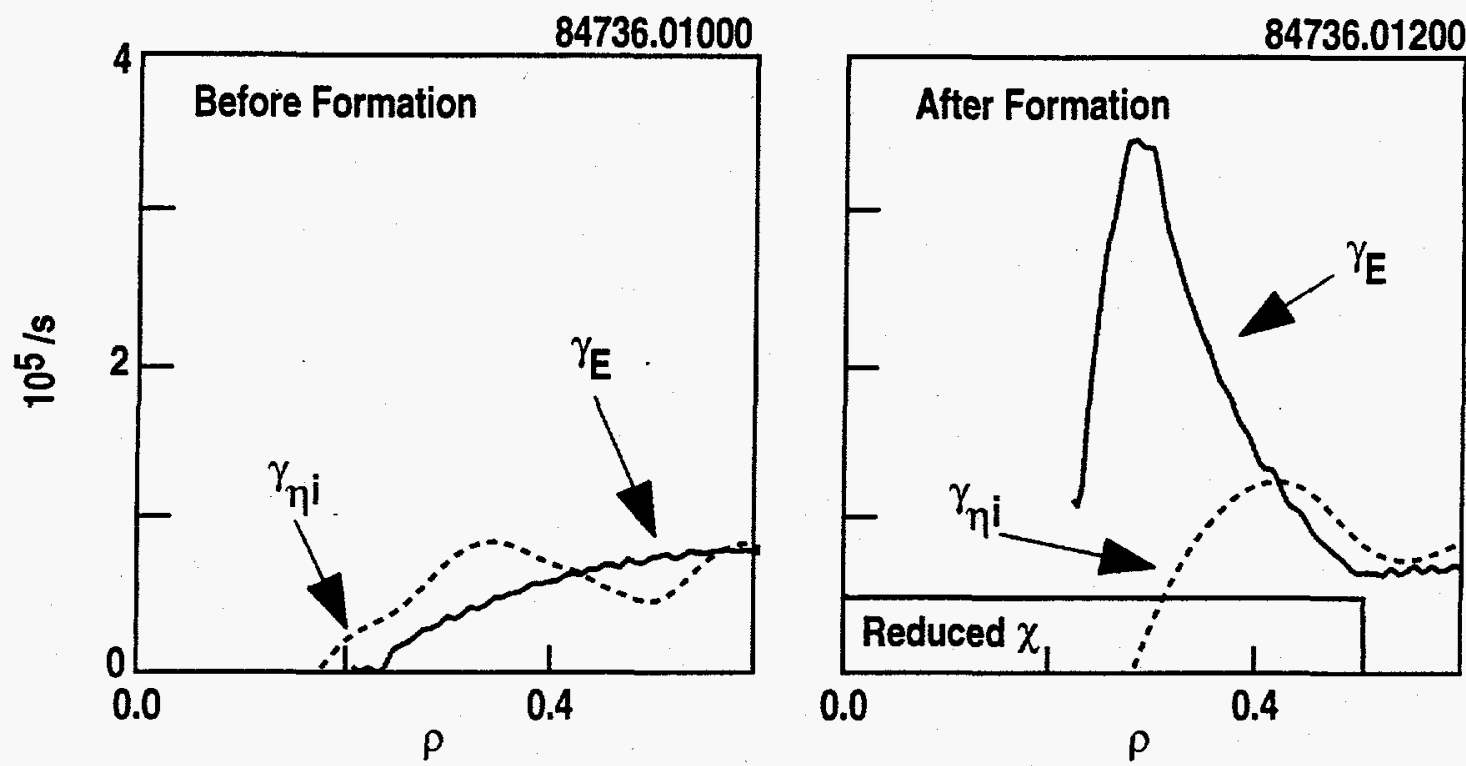

FIG. 5. Comparison of the growth rates of the toroidal drift mode (trapped-electron- $\eta_{\mathrm{i}}$ mode), $\gamma_{\eta \mathrm{i}}$, (dashed curves) before the formation of the core transport barrier at $1.0 \mathrm{~s}$ and after the formation at $1.2 \mathrm{~s}$ to the Doppler shift shear rate $\gamma_{E}=(\rho / q) \partial / \partial \rho\left(E_{r} / R B_{\theta}\right)$ (solid curves). The region of reduced thermal diffusivity $\chi$ is also shown.

formation of the barrier at $t=1.2 \mathrm{~s}, \gamma_{E}$ significantly exceeds $\gamma_{\eta \mathrm{i}}$ in the region where reduced transport is observed. From these results, we conclude that stabilization of microturbulence by ExB flow shear is the leading candidate to explain reduced core transport in these NCS discharges.

A reduction of core turbulence following the formation of core transport barrier is indicated from density fluctuation measurements from the far infrared (FIR) scattering diagnostic. A clear reduction in the core fluctuations is observed. A comparison of scattered spectra between a NCS discharge and a monotonic $\mathrm{q} \mathrm{H}$-mode discharge shows that after the $\mathrm{L}-\mathrm{H}$ transition, fluctuations are strongly suppressed over the entire plasma volume in the NCS discharge, whereas the core fluctuations clearly remain in the monotonic $\mathrm{q} H$-mode discharge. Initial density fluctuation measurements from both the beam emission spectroscopy (BES) system and the inside launch reflectometry system (utilizing the left hand cutoff) indicate that broadband turbulent fluctuation levels are at or below the system noise levels inside the negative central shear region of NCS discharges. This reduction of fluctuation amplitude in the region of reduced transport is consistent with ExB flow shear stabilization of turbulence. 


\section{MHD STABILITY OF NCS DISCHARGES}

The reduced core transport inside the negative shear region can lead to NCS discharges with very peaked pressure profiles $\mathrm{p}(0) /\langle\mathrm{p}\rangle>5$, which often disrupt when $\beta_{\mathrm{N}}$ reaches 2.0 to 2.5 over a range of $q_{\min }$ values, $1.3 \leq q_{\min } \leq 3.3$. A NCS discharge with an $L$-mode edge which disrupts when $\beta_{N} \sim 2, p(0) /\langle p\rangle \sim 5.7$, and $q_{\min } \sim 2.1$ is shown in Fig. 6 . The disruption is preceded by a fast growing rotating magnetic precursor with toroidal mode number $n=1$ and a growth time $\gamma^{-1} \approx 0.1-0.3 \mathrm{~ms}$, which approaches ideal time scales. This termination event cannot be explained by a simple picture of instability to an ideal $n=1$ mode. Ideal stability analysis computed using the GATO code 13 and equilibrium reconstructed experimentally from MSE and kinetic profile data shows that the discharge is stable to the $n=1$ mode with a conducting wall at the DIII-D vessel. The value of critical $\beta_{\mathrm{N}}$ unstable to the ideal $n=1$ mode is $10-20 \%$ above the experimental value.

Since these discharges are found to be stable to ideal modes, we examine the resistive stability of NCS discharges against the $n=1$ modes using the MARS code ${ }^{14}$ with both experimentally reconstructed as well as simulated equilibria. Two types of resistive modes have been identified: double tearing modes and resistive interchange modes. Double tearing modes have a global mode structure that extends across the plasma and may be stabilized by plasma rotation. Resistive interchange modes have a mode structure localized around the inner rational $\mathrm{q}$ surface and cannot be stabilized by plasma rotation.

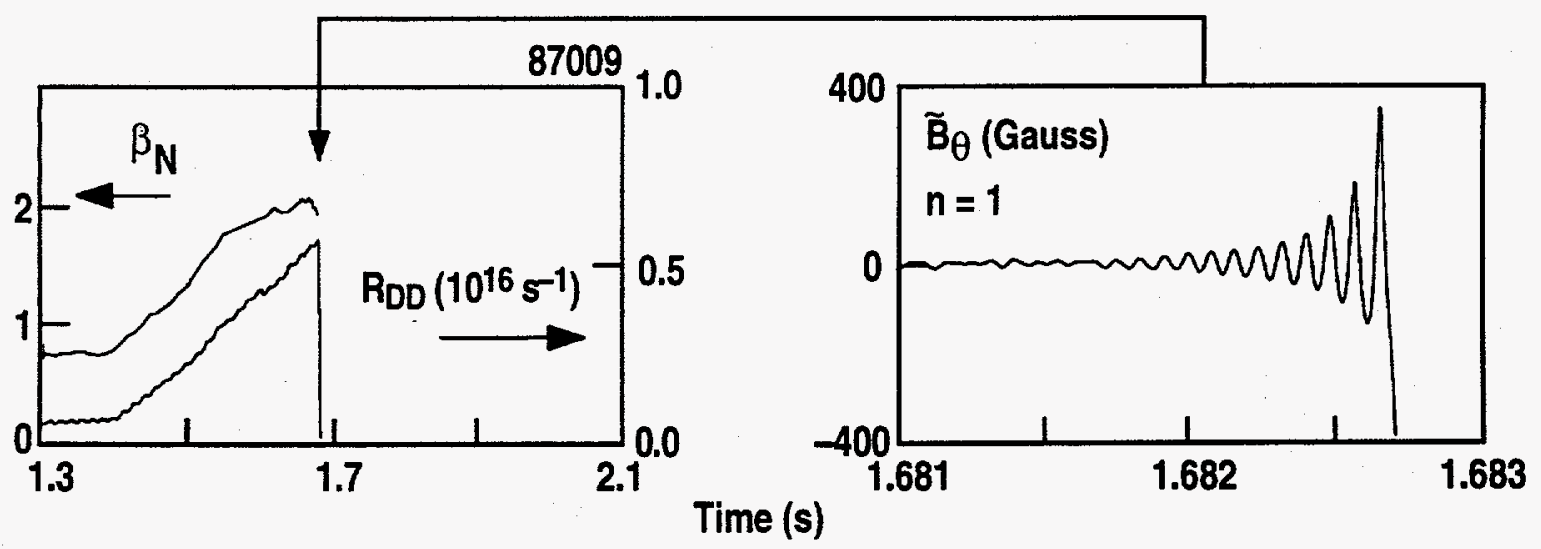

FIG. 6. Time traces of normalized beta $\beta_{N}$ and neutron yield $R_{D D}$ for L-mode NCS discharge 87009 showing a disruption preceded by a fast growing rotating $n=1$ magnetic precursor. 
Stability to resistive interchange modes is sensitive to the pressure profile peakedness and only depends weakly on the values of $q_{\min }$. These dependencies are illustrated in Fig. 7 where the stability boundary against the $n=1$ resistive interchange mode is shown in terms of $\beta_{\mathrm{N}}$ and $\mathrm{p}(0) /\langle\mathrm{p}\rangle$. The stability boundary is evaluated using a sequence of simulated NCS equilibria. These simulated equilibria are computed with $\mathrm{q}_{0}=\mathrm{q}_{\min }+1, \rho_{\mathrm{q}_{\min }} \sim 0.5,1.1 \leq \mathrm{q}_{\min } \leq 2.5$, $\mathrm{q}_{95} \sim$ $5.1, \kappa=1.8, \delta=0.7$, and $\mathrm{A}=2.5$. Here, $\rho_{\mathrm{q}_{\min }}$ is the normalized radius of $\mathrm{q}_{\min }, \mathrm{q}_{95}$ is the safety factor at $95 \%$ of the enclosed poloidal flux, $\mathrm{A}, \kappa$, and $\delta$ are the aspect ratio, elongation, and triangularity of the plasma poloidal cross section. As shown in Fig. 7, the stable $\beta_{\mathrm{N}}$ values decrease rapidly with increasing values of $\mathrm{p}(0) /\langle\mathrm{p}\rangle$. At $\mathrm{p}(0) /\langle\mathrm{p}\rangle>4.5$, the stable $\beta_{\mathrm{N}}$ becomes less than 2.3. The boundary varies only weakly with $\mathrm{q}_{\min }$ as shown in the inset. The weak dependence on $\mathrm{q}_{\min }$ is consistent with the experimentally observed disruptions. Also shown in Fig. 7 is the stability boundary against the $n=1$ ideal mode calculated with GATO ${ }^{13}$ which is $20-30 \%$ above the resistive interchange boundary. The ideal stability boundary is evaluated with a conducting wall located at $1.3 \mathrm{a}$.

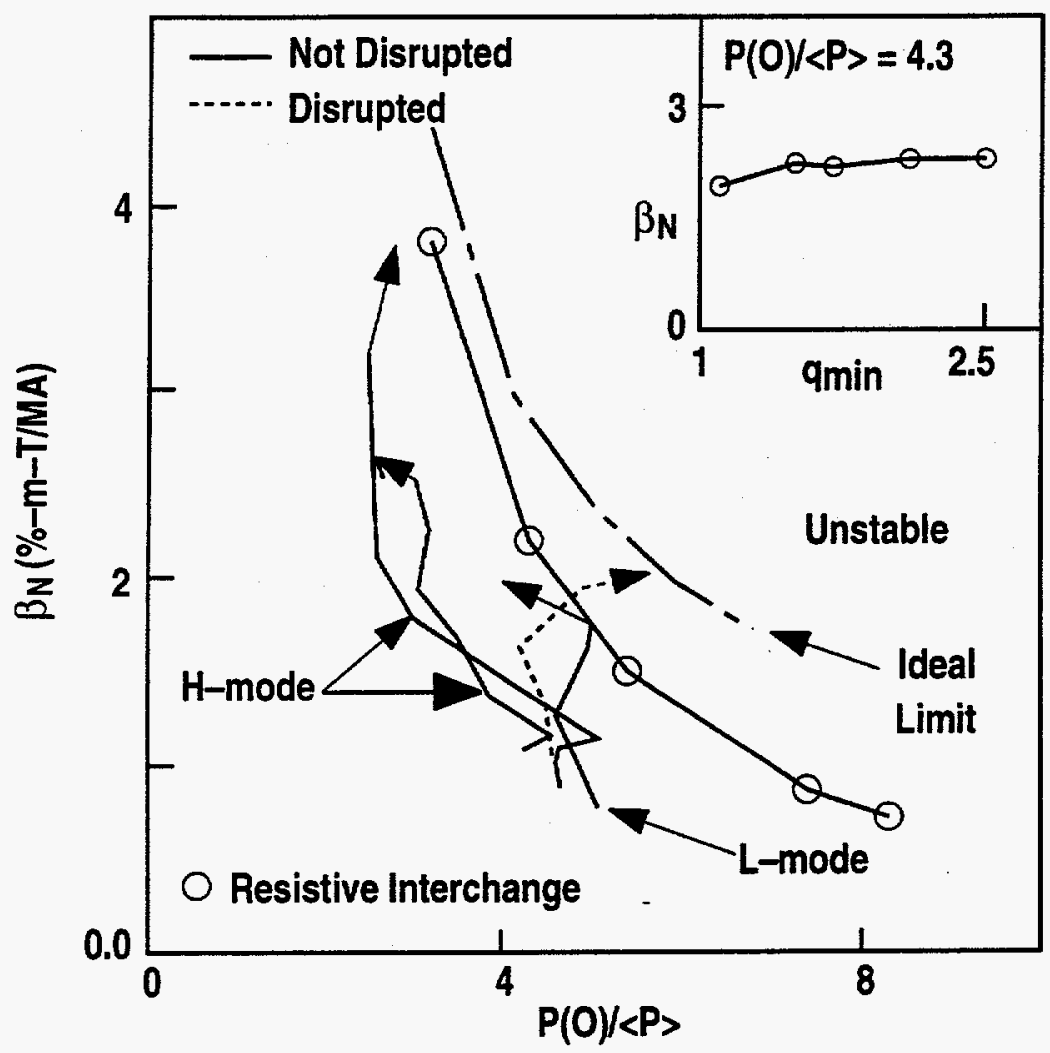

FIG. 7. Critical stable normalized beta $\beta_{\mathrm{N}}$ against the $n=1$ resistive interchange mode (open circles) and against the $n=1$ ideal kink mode (chain-dashed curve) as a function of the pressure profile peakedness $\mathrm{p}(0) /\langle\mathrm{p}\rangle$. Also shown are trajectories of three non-disrupted NCS discharges (solid curves) and a disrupted NCS discharge (dashed curve). The inset shows the insensitivity of the critical stable normalized beta $\beta_{\mathrm{N}}$ for the $n=1$ resistive interchange mode (open circles) to the variation of the minimum safety factor $\mathrm{q}_{\min }$. 
Also shown in Fig. 7 are the trajectories of two NCS H-mode discharges and two NCS discharges with an $\mathrm{L}$-mode edge. The two $\mathrm{H}$-mode discharges have broader pressure profiles and stay on the stable side of the resistive interchange stability boundary. They reach higher values of $\beta_{\mathrm{N}}$ and do not disrupt. The two discharges with an $\mathrm{L}$-mode edge have more peaked pressure profiles and reach lower values of $\beta_{\mathrm{N}}$. The $\mathrm{L}$-mode discharge that crosses the resistive stability boundary and disrupts (dashed trajectory) is the one shown in Fig. 6. This discharge appears to disrupt as it approaches the ideal stability boundary. Ideal stability analysis using more accurate experimentally reconstructed equilibria shows that the critical $\beta_{\mathrm{N}}$ is $10-20 \%$ above the experimental value.

The other L-mode discharge shown in Fig. 7 experiences a series of $n=1$ MHD bursts as it approaches the resistive interchange stability boundary. This is illustrated in Fig. 8. These oscillations are localized around the inner $q=3$ surface as indicated by the frequency of the MHD bursts and the sawtooth-like behavior seen on the MSE signals. At the MHD burst, the field pitch from the MSE channel at $q>3$ drops, and the field pitch from the MSE channel at $q<$ 3 increases. These responses are mostly observed in the MSE channels around the inner $q=3$ surface. These results indicate an inversion and localization of the mode at the $q=3$ surface. SXR analysis also indicates that the oscillations extend over a narrow region around the $q=3$ surface. As shown in Fig. 8, these bursts lead to reduction in both rotational shear and negative magnetic shear.

These stability calculations and experimental observations suggest that the resistive interchange interchange modes are likely responsible for the MHD bursts and may participate in the global termination events. Because of their localized nature they are unlikely to cause a disruption directly but may contribute to destabilization of global modes through modification of rotational and magnetic shear profiles. 

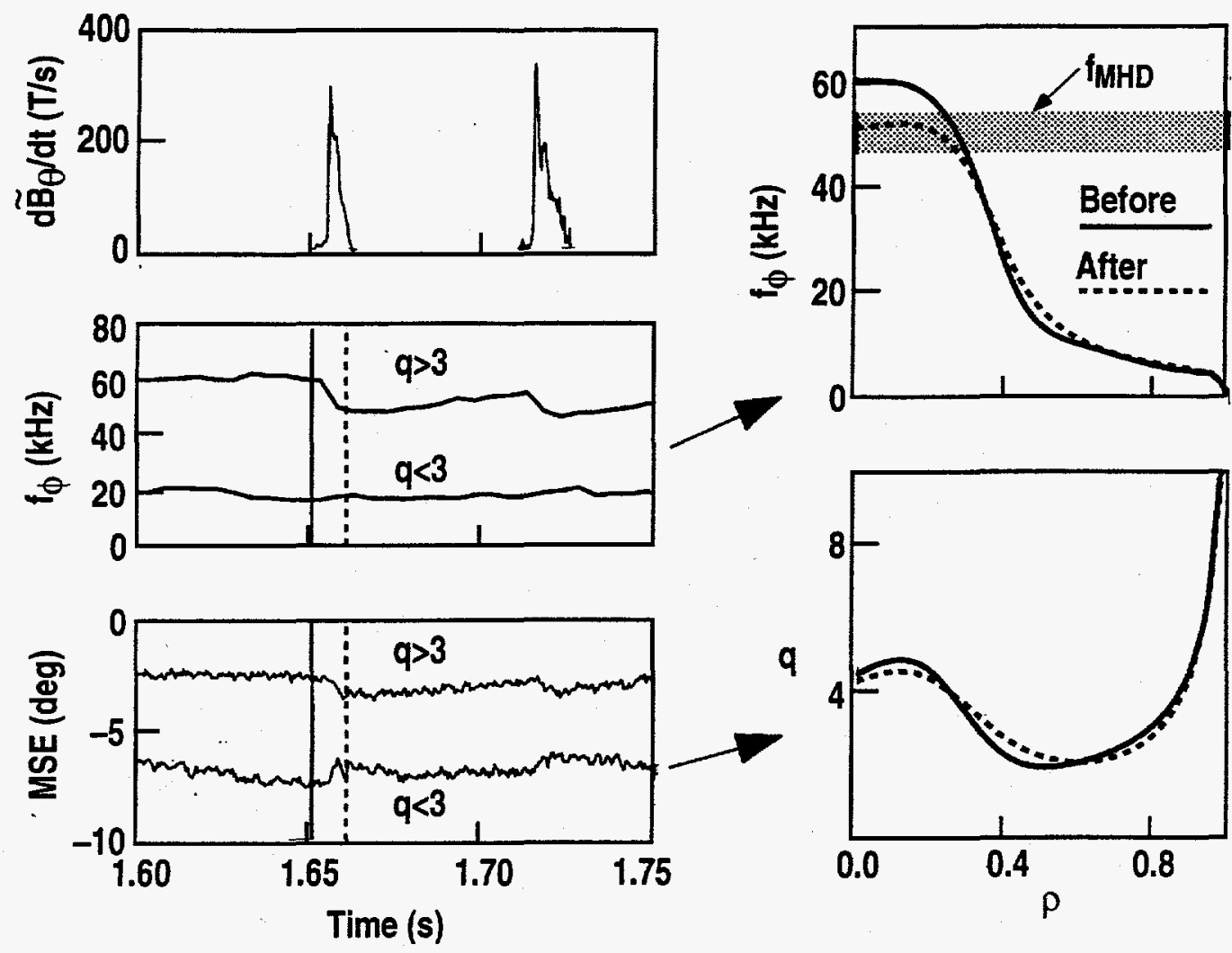

FIG. 8. Time traces of Mirnov signals $d \tilde{\mathrm{B}}_{\theta} / d t$, plasma rotation frequency in $\mathrm{kHz}, \mathrm{f}_{\phi}$, and the magnetic field line pitch angles from the Motional Stark Effect (MSE) diagnostic showing bursts of MHD activity localized near the inner $q=3$ surface which lead to reduction of rotational and magnetic shears. 


\section{WNS DISCHARGES}

In the DIII-D NCS experiments, a new class of discharges which have a broad region of weak or slightly negative magnetic shear has also been developed. L-mode NCS discharges terminate with a hard disruption as a consequence of excessive peaking of the pressure profile. The high performance phase of many ELM-free H-mode NCS discharges terminates with a fast growing MHD event initiated near the edge as a consequence of excessive pressure gradient and current density near the edge. WNS discharges are produced by optimizing the beam injection phase to reduce the build-up of current near the edge region while still allowing a $q$ profile with a broad region of weak or negative magnetic shear (WNS) to develop. WNS discharges are characterized by broader pressure profile with $\mathrm{p}(0) /\langle\mathrm{p}\rangle \sim 3$. These discharges have good confinement, high fusion reactivity, large fraction of bootstrap current, but higher $\beta$ values than NCS discharges.

The temporal evolution of a WNS discharge is given in Fig. 9. Unlike the NCS discharges shown in Fig. 1 which have very early beam injection during the current ramp up phase, the beam injection phase of the WNS discharge starts after the current flat-tops. As shown in Fig. 9, this beam timing results in a q profile with a broad region of weak or slightly negative magnetic shear around $\rho \sim 0.6$ but positive shear near the magnetic axis. Within the uncertainty of the measurement, the magnetic shear around $\rho \sim 0.6$ is weak or slightly negative (WNS). This discharge reaches values of $\beta_{\mathrm{N}}>4.5$ and $H>3.5$, which are among the highest values achieved by an $\mathrm{H}$ - or a VH-mode discharge in DIII-D. It also has a high fraction $\sim 80 \%$ of noninductively driven current. The onset of edge localized modes (ELMs) near time $t=2.1 \mathrm{~s}$ leads to oscillations of $\beta_{\mathrm{N}}$ and $H$ rather than immediate collapses to lower levels as is usually observed in VH-mode discharges. The discharge shows strong evidence of wall stabilization. Ideal stability analysis shows that it is strongly unstable to the ideal $n=1$ mode without a conducting wall and stable with a wall at the DIII-D vessel. As shown in Fig. 10, WNS discharges have a wider region of second ballooning stability access than the usual VH-mode discharges due to the broad region of weak or slightly negative magnetic shear. ${ }^{21,22}$ The stability boundary is evaluated using the CAMINO code. 23 


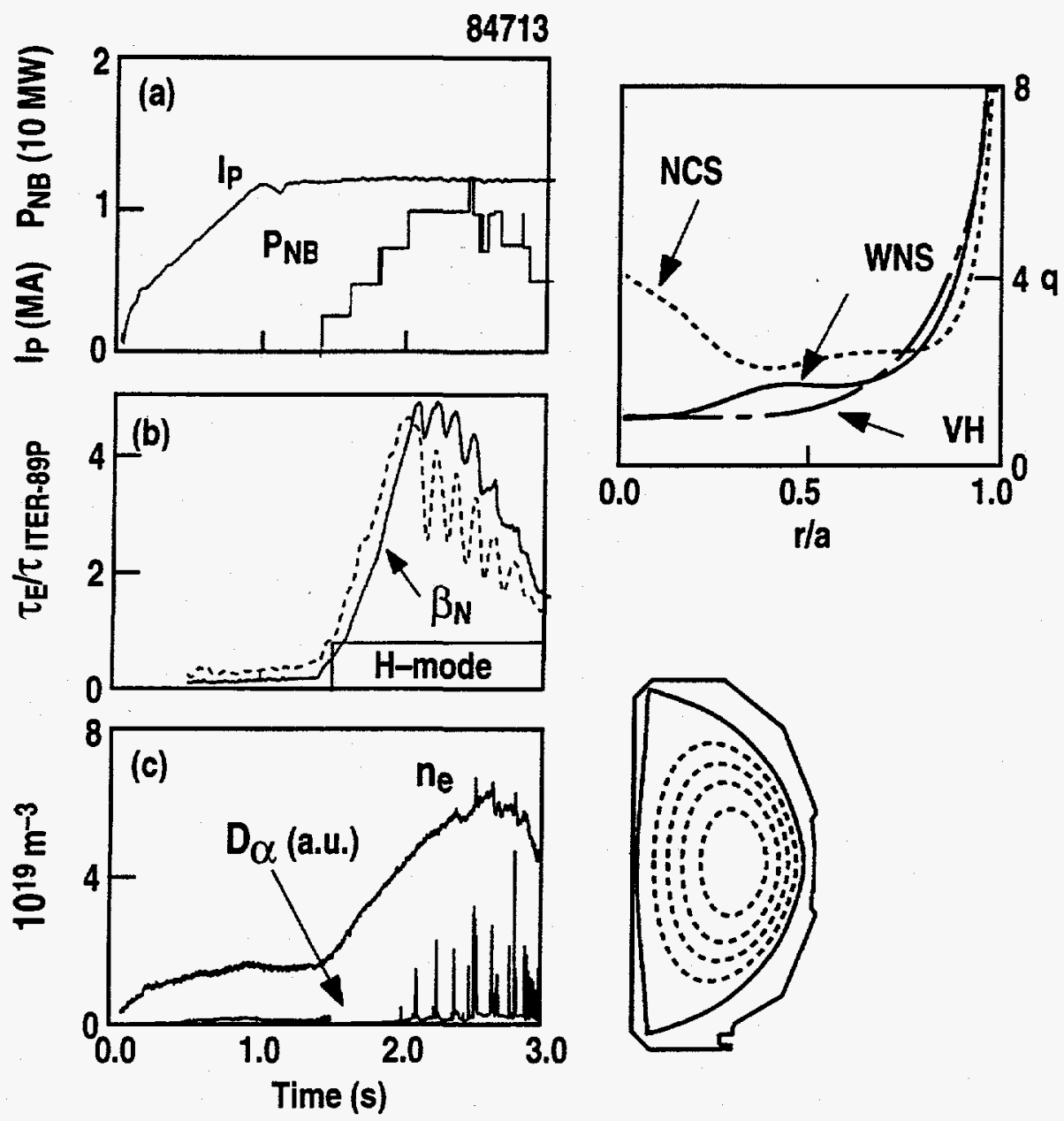

FIG. 9. Temporal evolution of WNS discharge 84713. (a) Plasma current $I_{P}$ and injected neutral beam power, $\mathrm{P}_{\mathrm{NB}}$. (b) Energy confinement time normalized with respect to the L-mode ITER-89P scaling $\tau_{E} / \tau_{\text {ITER-89P }}$ and normalized beta $\beta_{N}$ (\%-m-T/MA). (c) Electron density $n_{e}$ and $D_{\alpha}$ radiation. The $q$ profile at the peaked $\beta$ time $t=2.08 \mathrm{~s}$ is compared to that of a NCS discharge and a usual VH-mode discharge. Also shown are the equilibrium flux surfaces at $t=2.08 \mathrm{~s}$.

In the central region of the WNS discharge $\rho \sim 0.3$, the strong positive shear pushes the plasma back into the first ballooning stability regime. This reduces the peakedness of the pressure profiles in WNS discharges and may contribute to the higher performance of WNS discharges comparing with NCS discharges. 

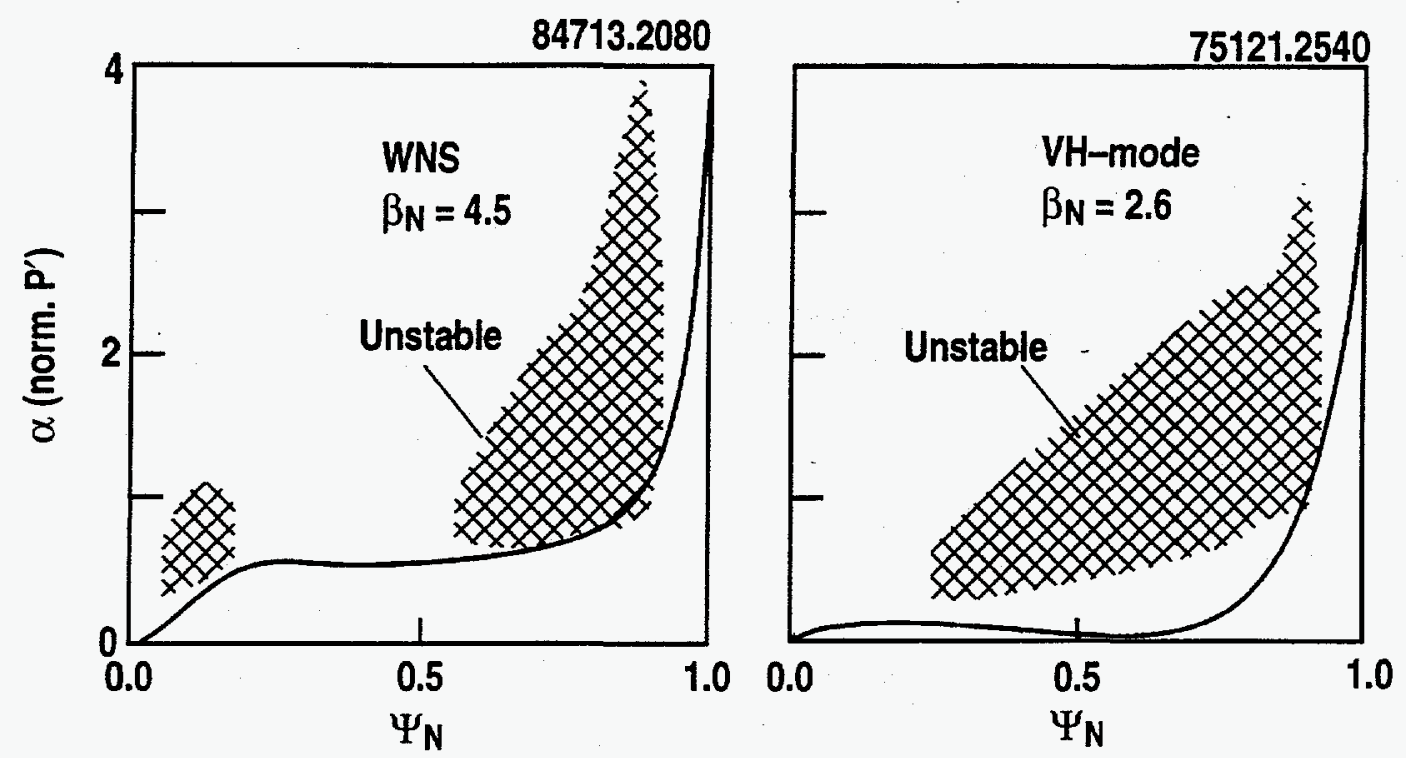

FIG. 10. Comparison of the ideal ballooning stability boundaries of WNS discharge 84713 and a usual VH-mode discharge. $\alpha$ and $\Psi_{\mathrm{N}}$ are the normalized pressure gradient and the normalized poloidal flux. The shaded regions are the unstable areas. The experimental profiles are shown as solid curves.

In Fig. 11, the ion thermal diffusivity of this WNS discharge near the peaked $\beta$ time is compared to that of the NCS discharge at the $\mathrm{H}$-mode time shown in Fig. 3. The WNS discharge has a smaller value of $\chi_{\mathrm{i}}$ in the region $0.5<\rho<0.8$ but a larger value in the core. In the region $0.5<\rho<0.8, \chi_{\mathrm{i}}$ for the WNS discharge is near the neoclassical value. Simulations have indicated that the reduction of transport in this region is beneficial for good bootstrap alignment in high $\beta$ high performance discharges. 


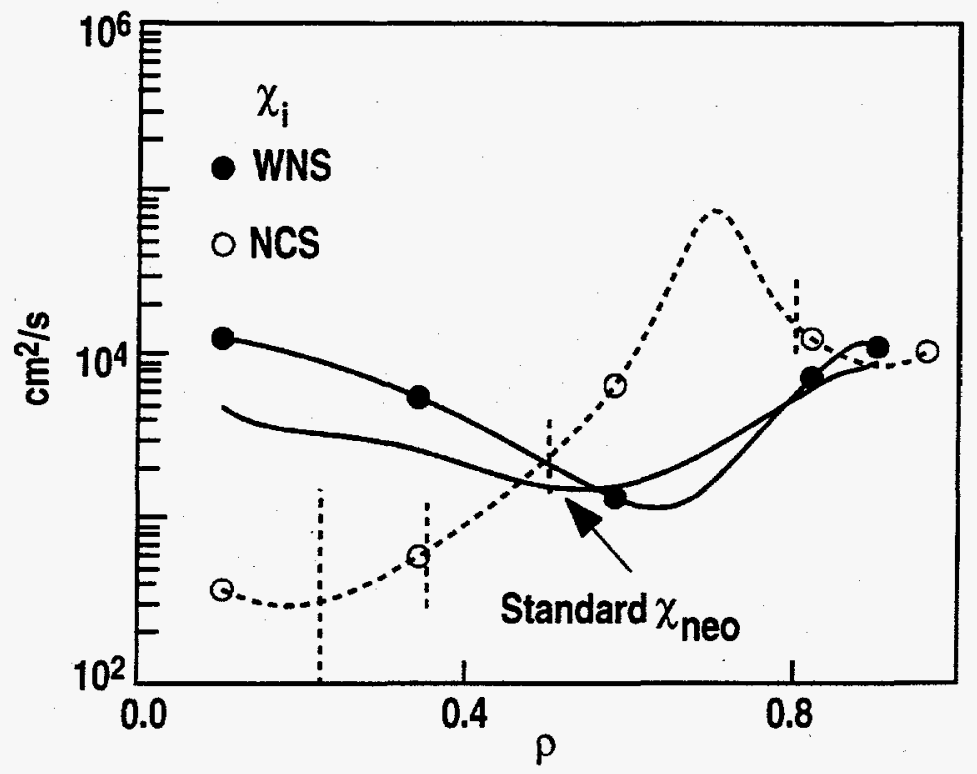

FIG. 11. Comparison of ion thermal diffusivity of WNS discharge 84713 at the $\mathrm{H}$-mode time $2.1 \mathrm{~s}$ (solid circles) against that of NCS discharge 84736 at the $\mathrm{H}$-mode time $1.4 \mathrm{~s}$ (open circles). The standard neoclassical ion thermal diffusivity $\chi_{\text {neo }}$ is shown in solid curve. 


\section{SUMMARY}

Increasing the magnitude of negative central magnetic shear contributes to the formation of the core transport barrier often observed in the NCS discharges. Stabilization effect on the toroidal drift mode (trapped-electron- $\eta_{i}$ mode) by the negative magnetic shear alone is not sufficient to explain this formation. Comparison of the Doppler shift shear rate to the growth rate of the $\eta_{i}$ mode suggests that the large core ExB flow shear can stabilize this mode and broaden the region of reduced core transport. The reduction of fluctuation amplitude in the region of reduced transport is consistent with ExB flow shear stabilization of turbulence.

The reduced core transport inside the negative shear region can lead to NCS discharges with very peaked pressure profiles. Ideal and resistive stability analysis indicate the performance of NCS discharges with strongly peaked pressure profiles is limited by the resistive interchange mode to low $\beta_{\mathrm{N}} \leq 2.3$ when $\mathrm{p}(0) /\langle\mathrm{p}\rangle \gtrsim 4.5$, consistent with experimental observations. This mode is insensitive to the details of the rotational and the magnetic shear profiles. Improved current and pressure profile controls are needed for avoidance of low $n$ instabilities to make full use of the enhanced core confinement.

A new class of discharges have been developed which offers the possibility of enhanced stability and improved boostrap current alignment for steady-state operation, while still maintaining good confinement and high performance. These have a broad region of weak or slightly negative magnetic shear (WNS). $\beta_{\mathrm{N}} \sim 5$ has been achieved in these discharges. Transport is greatly reduced in the mid-radius $0.5<\rho<0.8$ to near neoclassical values. 


\section{REFERENCES}

${ }^{1}$ A. D. Turnbull, T. S. Taylor, Y. R. Lin-Liu, and H. St. John, Phys. Rev. Lett. 73, 718 (1995).

${ }^{2}$ C. Kessel, J. Manickam, G. Rewoldt, and W. M. Tang, Phys. Rev. Lett. 72, 1212 (1994).

3J. L. Luxon, R. Anderson, F. Batty, C. B. Baxi, G. Bramson, N. H. Brooks, B. Brown, B. Burley, K. H. Burrell, R.W. Callis, G. L. Campbell, T. N. Carlstrom, A. P. Colleraine, J. Cummings, L. Davis, J. C. DeBoo, S. Ejima, R. Evanko, H. Fukumoto, R. Gallix, J. Gilleland, T. Glad, P. Gohil, A. M. Gootgeld, R. J. Groebner, S. Hanai, J. Haskovec, E. Heckman, M. Heilberger, F. J. Helton, N. Hosogane, C.-L. Hsieh, G. L. Jackson, G. Jahns, G. Janeschitz, E. Johnson, A. G. Kellman, J. S. Kim, J. Kohli, A. Langhorn, L. L. Lao, P. Leek, S. Lightner, J. Lohr, M. A. Mahdavi, M. Mayberry, B. McHarg, T. McKelvey, R. Miller, C. P. Moeller, D. Moore, A. Nerem, P. Noll, T. Ohkawa, N. Ohyabu, T. H. Osborne, D. O. Overskei, P. I. Petersen, T. W. Petrie, J. Phillips, R. Prater, J. Rawls, E. E. Reis, D. Remsen, P. Riedy, P. Rock, K. Schaubel, D. P. Schissel, J. T. Scoville, R. Seraydarian, M. Shimada, T. Shoji, B. Sleaford, J. P. Smith, T. Smith, R. T. Snider, R. D. Stambaugh, R. Stav, H. St. John, R. E. Stockdale, E. J. Strait, R. Stree, T. S. Taylor, J. Tooker, M. Tupper, S. K. Wong and S. Yamaguchi, Plasma Phys. and Contr. Nucl. Fusion Research, 1986 (International Atomic Energy Agency, Vienna, 1987), Vol. I, p. 159.

${ }^{4}$ B. W. Rice, T. S. Taylor, K. H. Burrell, T. A. Casper, M. S. Chu, L. L. Lao, E. A. Lazarus, M. E. Mauel, T. H.Osborne, B. W. Stallard, E. J. Strait, A. D. Turnbull, "The Formation and Evolution of Negative Central Shear Current Profiles in the DIII-D Tokamak," General Atomics Report GA-A22127, submitted to Plasma Phys. and Contr. Fusion.

${ }^{5}$ E. J. Strait, L. L. Lao, M. E. Mauel, B. W. Rice, T. S. Taylor, K. H. Burrell, M. S. Chu, E. A. Lazarus, T. H. Osborne, S. J. Thompson, and A. D. Turnbull, Phys. Rev. Lett. 75, 4421 (1995).

${ }^{6}$ B. W. Rice, E. A. Lazarus, K. H. Burrell, T. A. Casper, M. S. Chu, L. L. Lao, M. E. Mauel, T. H. Osborne, B. W. Stallard, E. J. Strait, T. S. Taylor, A. D. Turnbull, “Observations of Enhanced Core Confinement in Negative Magnetic Shear Discharges With an L-Mode Edge on DIII-D," General Atomics Report GA-22129, submitted to Nucl. Fusion.

${ }^{7}$ R. J. Hawryluk, D. Mueller, J. Hosea, C. W. Barnes, M. Beer, M. G. Bell, R. Bell, H. Biglari, M. Bitter, R. Boivin, N. L. Bretz, R. Budny, C. E. Bush, L. Chen, C. Z. Cheng, S.C. Cowley, D. S. Darrow, P. C. Efthimion, R. J. Fonck, E. Fredrickson, H. P. Furth, G. Greene, B. Grek, 
L. R. Grisham, G. Hammett, W. W. Heidbrink, K. W. Hill, D. Hoffman, R. A. Hulse, H. Hsuan, A. Janos, D. L. Jassby, F. C. Jobes, D. W. Johnson, L. C. Johnson, J. Kamperschroer, J. Kesner, C. K. Phillips, S. J. Kilpatrick. H. Kugel, P. H. Lamarche, B. LeBlanc, D. M. Manos, D. K. Mansfield, E. S. Marmar, E. Mazzucato, M. P. McCarthy, J. Machuzak, M. Mauel, D. C. McCune, K. M. McGuire, S. S. Medley, D. R. Mikkelsen, D.A. Monticello, Y. Nagayama, G. A. Navratil, R. Nazikian, D. K. Owens, H. Park, W. Park, S. Paul, F. W. Perkins, S.Pitcher, D. Rasmussen, M. H. Redi, G. Rewoldt, D. Roberts, A. L. Roquemore, S. Sabbagh, G. Schilling, J. Schivell, G. L. Schmidt, S. D. Scott, J. Snipes, J. Stevens, B. C. Stratton, J. D. Strachan, W. Stodiek, E. Synakowski, W. Tang, G. Taylor, J. Terry, J. R. Timberlake, H. H. Towner, M. Ulrickson, S. Von Goeller, R. M. Wieland, J. R. Wilson, K.L. Wong, P. Woskov, M. Yamada, K. M. Young, M. C. Zarnstorff, and S.J. Zweben, Fusion Technol. 21, 1324 (1992).

8F. M. Levinton, M. C. Zarnstorff, S. H. Batha, M. Bell, R. E. Bell, R. V. Budny, C. Bush, Z. Chang, E. Fredrickson, A. Janos, J. Manickam, A. Ramsey, S. A. Sabbagh, G. L. Schmidt, E. J. Synakowski, and G. Taylor, Phys. Rev. Lett. 75, 4417 (1995).

${ }^{9}$ P. A. Politzer, T. Casper, C. B. Forest, P. Gohil, W. W. Heidbrink, A. W. Hyatt, R. A. James, R. Jong, L. L. Lao, M. Makowski, W. Meyer, G. D. Porter, G. T. Sager, B. W. Stallard, H. St. John, S. J. Thompson, A. D. Turnbull, D. Wroblewski, Phys. Plasmas 1, 1545 (1994).

${ }^{10}$ B. W. Rice, K. H. Burrell, L. L. Lao, G. Navratil, B. W. Stallard, E. J. Strait, T. S. Taylor, M. E. Austin, T. A. Casper, M. S. Chu, C. B. Forest, P. Gohil, R. J. Groebner, W. W. Heidbrink, A. W. Hyatt, H. Ikezi, R. J. La Haye, E. A. Lazarus, Y. R. Lin-Liu, M. E. Mauel, W. H. Meyer, C. L. Rettig, D. P. Schissel, H. E. St. John, P. L. Taylor, A. D. Turnbull, and the DIII-D Team, "Demonstration of High Performance Negative Central Magnetic Shear Discharges on the DIII-D Tokamak," General Atomics Report GA-A22257, submitted to Phys. Plasmas (special DPP issue).

11B. B. Kadomtsev and O. P. Pogutse, Soviet Physics JETP 24, 1172 (1967).

12 M. N. Rosenbluth and M. L. Sloan, Phys. Fluids 14, 1725 (1971).

${ }^{13}$ L. C. Bernard, F. J. Helton, R. W. Moore, Comput Phys. Commun. 24, 377 (1981).

14A. Bondeson, and D. J. Ward, Phys. Rev. Lett. 72, 2709 (1993); M. Chu, J. Greene, W. Ling, A. D. Turnbull, H. L. Berk, and M. N. Rosenbluth, Phys. Plasmas 1, 1214 (1994).

15P. N. Yushmanov, T. Tkizuka, K. S. Riedel, O. J. W. F. Kardaun, J. G. Cordey, S. M. Kaye, D. E. Post, Nucl. Fusion 30, 1999 (1990).

16B. W. Rice, D. G. Nilson, and D. Wroblewski, Rev. Sci. Instrum. 66, 373 (1995b).

${ }^{17}$ L. L. Lao, J. R. Ferron, R. J. Groebner, W. Howl, H. St. John, E. J. Strait, and T. S. Taylor, Nucl. Fusion 30, 1035 (1990). 
${ }^{18}$ G. Rewoldt, W. M. Tang, and M. S. Chance, Phys. Fluids 25, 480 (1982).

${ }^{19}$ T. S. Hahm and K. H. Burrell, Phys. Plasmas 2, 1648 (1995).

${ }^{20}$ R. E. Waltz, G. D. Kerbel, J. Milovich, and G. W. Hammett, Phys. Plasmas 2, 2408 (1995).

${ }^{21}$ A. Sykes, J. A. Wesson, and S. J. Connor, Phys. Rev. Lett. 39, 757 (1977).

22J. M. Greene and M. S. Chance, Nucl. Fusion 21, 453 (1981).

${ }^{23}$ M. S. Chance, in Proceedings of Theory of Fusion Plasma, 1987 (Societa Italiana di Fisca, Bologona, Italy, 1988) Vol. 18, p. 87. 


\section{ACKNOWLEDGMENTS}

This is a report of research supported by the U.S. Department of Energy under Contract Nos. DE-AC03-89ER51114, W-7405-ENG-48, DE-AC05-84OR21400, and Grant Nos. DEFG02-89ER53297 and DE-FG03-86ER53266. 